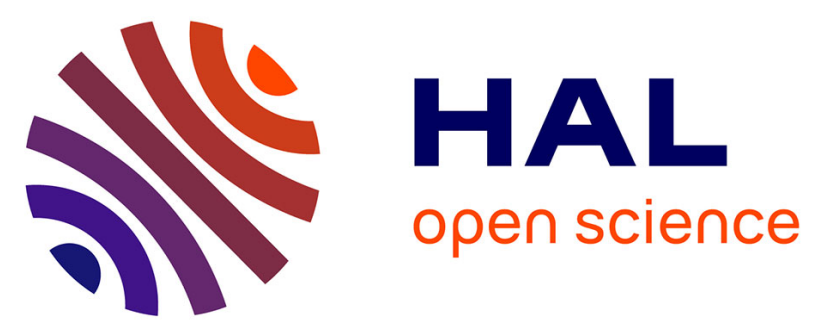

\title{
Neonatal probiotic administration has long-lasting effects on gut permeability responses to stress in adult pigs born to sows treated with antibiotics around parturition
}

Jean Paul Lalles, Dominique Bertacchini, Gérard Savary, Hauke Smidt

\section{To cite this version:}

Jean Paul Lalles, Dominique Bertacchini, Gérard Savary, Hauke Smidt. Neonatal probiotic administration has long-lasting effects on gut permeability responses to stress in adult pigs born to sows treated with antibiotics around parturition. Digestive disease week, May 2013, Orlando, United States. Gastroenterology, 144 (5) (Suppl.1), 2013, Gastroenterology. 10.1016/S0016-5085(13)63375-2 . hal01594167

\section{HAL Id: hal-01594167 \\ https://hal.science/hal-01594167}

Submitted on 3 Jun 2020

HAL is a multi-disciplinary open access archive for the deposit and dissemination of scientific research documents, whether they are published or not. The documents may come from teaching and research institutions in France or abroad, or from public or private research centers.
L'archive ouverte pluridisciplinaire HAL, est destinée au dépôt et à la diffusion de documents scientifiques de niveau recherche, publiés ou non, émanant des établissements d'enseignement et de recherche français ou étrangers, des laboratoires publics ou privés.

\section{다(1)(2)}

Distributed under a Creative Commons Attribution - ShareAlikel 4.0 International 
around parturition (d-10 till $\mathrm{d}+21)$. Offspring (1/litter) were sacrificed during the suckling period (d14, d28) and after weaning (d42), and ileal tissues were collected. HSP27, HSP60, HSP70 and cognate HSC70, as well as the transcription factor HSFl were determined by western blotting and tissue levels expressed relative to $\beta$-actin. Enzyme activity of intestinal alkaline phosphatase (IAP), an HSP-like protein crucial in the detoxification of pro-inflammatory bacterial components (e.g. LPS) was also investigated in comparison. Results: Ileal tissue levels of HSP27 in offspring were unaffected by antibiotic treatment of mothers. HSP60 tended to be $(\mathrm{P}=0.07)$ and $\mathrm{HSC} 70$ was $(\mathrm{P}<0.05)$ higher in offspring born to ATBQ sows than in CTL (+40 and $+24 \%$, respectively). By contrast, HSP70 was much lower in offspring born to ATBQ sows than in CTL $(\mathrm{P}<0.01)$ and this difference was significant $(\mathrm{P}<0.01)$ at day $28(-69 \%)$ and day $42(-59 \%)$ (treatment by age interaction, $\mathrm{P}<0.05)$. Ileal protein expression of HSFl in offspring was unaffected by ATBQ treatment of sows or offspring post-natal age. In comparison to HSPs, IAP activity displayed a treatment by time interaction: it was twice lower at day 14 in offspring born to ATBQ sows than in CTL $(P<0.01)$ with no differences at days 28 and 42 . Conclusion: Maternal antibiotic treatment peripartum had differential consequences on protein expression of intestinal heat shock proteins in her offspring in the swine. This did not involve the modulation of HSP-gene transcription factor HSFl, suggesting alternate regulatory mechanisms. Collectively, the data suggest complex, time-dependent interactions between colonizing maternal fecal microbiota and offspring intestinal HSP expression. Changes in offspring intestinal microbiota and long-term effects of perinatal antibiotic treatment on offspring intestinal HSP family are being investigated.

\section{Tu2019}

Neonatal Probiotic Administration Has Long-Lasting Effects on Gut Permeability Responses to Stress in Adult Pigs Born to Sows Treated With Antibiotics Around Parturition

Jean-Paul Lalles, Dominique Bertacchini, Gerard Savary, Hauke Smidt

Background: Peripartum antibiotics are thought to have long-lasting negative consequences on intestinal barrier function, immune system development and long-term health, e.g. allergy. Various kinds of stress (e.g. nutrition, environment) can be deleterious to gut barrier function. We have shown that broad spectrum antibiotic administration to sows around parturition alters various facets of gut barrier in their offspring during development and in adulthood. We tested with this model the hypothesis that early administration of a probiotic to offspring can modulate gut barrier function in young adults depending on diet and stressor. Methods: Sows $(n=20)$ received amoxicillin orally $(40 \mathrm{mg} / \mathrm{kgBW} / \mathrm{d}$ ) around parturition (day-10 to day+21) in order to induce gut barrier disturbances in offspring. Piglets from half of the litters received orally a probiotic suspension (Lactobacillus sobrius, 108/ml, $1 \mathrm{ml} /$ pig and intervention, PROB) at birth and then three times a week until postnatal day PND21. Offspring were reared under the sow until weaning at PND28. They were reared with a similar diet until PND141. Then, each group was split into two halves. One half in each group remained on the control (low fat, LF 2\%) diet while the other halves were fed a high fat (HF, 11\%) diet. Pigs were sacrificed at PNDl69 and pieces of ileum and colon were collected and mounted in Ussing chambers (UC). UC treatment included control, oxidative stress (monochloramine) and mast cell degranulation stress (48/80). Mucosal para- and trans-cellular permeabilities (PCP, TCP) were measured using FD4 and HRP, respectively. Results: Early PROB supplementation had no effect on offspring basal ileal and colonic permeabilities. Ileum from PROB pigs fed LF diet displayed reduced PCP in oxidative $(\mathrm{P}<0.05)$ and degranulation $(\mathrm{P}<0.10)$ conditions. No differences between PROB and CTL were seen for colonic PCP. Contrasting with this, ileal TCP was much higher ( $\mathrm{x} 2$ to 3 ) in PROB pigs with both LF and HF diets $(\mathrm{P}<0.01)$ after degranulation stress. An interaction $(\mathrm{P}<0.10)$ between early PROB treatment and adult diet was observed for TCP after oxidative stress (decrease with LF, increase with HF). Colonic TCP was increased after both oxidative and degranulation stress in PROB pigs fed LF (but not HF) diet $(\mathrm{P}<0.05)$. Conclusion: Our data in the swine model suggest that probiotics provided early to gut barrier-disturbed offspring born to mothers treated with broad-spectrum antibiotic around parturition can contribute to long-term modulation of gut barrier function following stress. However, the responses are complex and depend on gut site, and diet composition and type of stressor in adluthood. Work is in progress to investigate long-term changes in gut microbiota composition induced by early probiotic administration.

\section{Tu2020}

Chronic Ingestion of Lactose: Malabsorber Host and Intestinal Microbiota Adaptations

Virginie Alexandre, Annaig Lan, François Blachier, Robert Benamouzig, Yolanda Sanz, Daniel Tomé, Anne-Marie Davila

Introduction: Physiological and metabolic consequences of chronic lactose ingestion by malabsorbers are poorly described. In order to highlight the suspected modulations and adaptations, intestinal microbiota and host's physiology have been in vivo studied in hypolactasic rats, over a prolonged ingestion of lactose. Materials and methods: Two groups of Wistar male rats ingested a diet containing $25 \%$ of lactose (L25 group) or $25 \%$ of sucrose (pair-fed S25 group). Consecutive slaughters were performed over 6 days of the diet. Bacterial groups' evolutions (qPCR), short-chain-fatty-acids (SCFA) concentrations and $\beta$ galactosidase activity were evaluated in caecal and colonic contents. Concomitantly, SCFA were quantified in portal blood, myeloperoxydase activity (MPO) was evaluated in colonic mucosa and histological samples were analysed. Results: L25 vs S25 comparisons over time reveal a stability of the total counts of bacteria, despite proliferations of fermentative groups with or without $\beta$ galactosidase activity, with a segment-dependent dynamic. In the L25 group, Bacteroides predominate in caecum and distal colon (diet effect $\mathrm{p}<10-4$ ). In proximal colon, groups' evolutions are noticed but stimulate at day 6: Bacteroides, enterobacteria, lactobacilli (diet effect $\mathrm{p}<10-4)$. Sulfate-reducing bacteria decrease in all segments in favour of acetogenic bacteria in caecum and proximal colon, and also archeae methanogens in distal colon (diet effect $\mathrm{p}<10-4$ ). Consecutively, $\beta$ galactosidase activity is higher in caecum of L25 group (time*diet effect $\mathrm{p}<0.05$ ). Moreover, SCFA colonic concentrations become significantly higher in L25 group, with a time* diet effect in caecum $(\mathrm{p}<0.05)$ and distal colon $(\mathrm{p}=0.002)$. SCFA blood concentrations significantly increase at day 1 , then stabilise at day 2 . At last,
MPO activity and mucosa histology underline a transitional inflammation at days 1 and 2 in the L25 group, especially with an MPO activity higher in proximal colon $(\mathrm{p}=0.04)$ and distal colon ( $\mathrm{p}=0.03)$, a smaller ratio (mucosa area/ section area) $(\mathrm{p}=0.03)$ and a higher ratio (goblet cells/ colonocytes) ( $\mathrm{p}=0.04)$. Conclusions: Prolonged lactose ingestion modifies both composition and activity of the intestinal microbiota, stimulating a turn-over of the lactose colonic metabolites and a reduction of the mucosa inflammation. These findings underline the roles of microbiota-host interplays and suggest that small but regular amounts of lactose could improve the malabsorber host's tolerance.

\section{$\mathrm{Tu} 2021$}

Intestinal Epithelial Cells Apically Secrete Exosomes Taken up by Neighboring Epithelial Cells and Bacteria

Poonam Rakhya, Bo Xiao, Hamed Laroui, Didier Merlin

Background and Aims: Exosomes are small membrane vesicles of endosomal origin secreted from a variety of cell types. Exosomes contain proteins, mRNAs, and microRNAs, and may play roles as mediators of cell-to-cell communication. Herein, we characterized exosomes secreted by intestinal epithelial cells and investigated exosome uptake by epithelial cells and bacteria. Methods: Release of exosomes from Caco2-BBE monolayers grown under basal or inflammatory conditions was evaluated by differential ultracentrifugation after growth of such cells in conditioned apical and basolateral media. Exosome size and morphology were assessed employing light-scattering techniques, atomic force microscopy, and scanning electron microscopy. The exosomal marker CD63 was used to assess the purity of exosome preparations. Fluorescent microscopy was employed to visualize intracellular uptake of secreted Caco2-BBE exosomes (fluorescently labeled by electroporation of FITC-siRNA complexed with PEI) by macrophages RAW264.7, Caco2-BBE monolayers, and bacteria. Results: Caco2-BBE cell monolayers released vesicles $80-150 \mathrm{~nm}$ in diameter bearing the exosomal marker CD63 from the apical but not from the basolateral side, and the extent of such release was increased when the monolayers were pre-stimulated with LPS $(10 \mathrm{ng} / \mathrm{mL}$ for 4h). FITC-labeled secreted exosomes from Caco2-BBE monolayers were taken up by such monolayers (70\%), macrophages (30\%), and bacteria. Conclusion: Caco2-BBE cell monolayers specifically secrete exosomes toward the luminal side of the intestinal cell monolayer. Such apical exosome secretion by intestinal epithelial cells is a regulated process. Secreted exosomes may fuse with neighboring epithelial cells, thus transferring membranous and cytoplasmic contents from one cell to another, and may also be taken up by bacteria of the colonic lumen. Secreted exosomes may play key roles in epithelial cell/cell and epithelial cell/bacterium communication under pathophysiological conditions.

\section{Tu2022}

Role of Food and Enterobacteria in the Formation and Prevention of Small Intestinal Lesions Induced by Enteric Coated Aspirin in Cats Hiroshi Satoh, Kikuko Amagase, Ami Yokoi, Taiki Kawabata, Koji Takeuchi

BACKGROUND/AIM: Recently, low-dose aspirin (ASA) has been widely used as the firstchoice drug for the prophylaxis and treatment of thrombosis. Enteric-coated (EC) ASA has been used to limit gastric lesions as a side effect, but even low doses of EC ASA often cause mucosal damage in the small intestine in humans. However, there are few studies on the role of food and enterobacteria in the formation and prevention of the intestinal damage. We examined the effect of various foods and antibiotic on the formation of intestinal lesions induced by EC-ASA in cats. METHODS: Adult cats were used (4 to 6 animals per group). Several types of diet containing dietary fiber (DF) at various percentages were given to the animals twice daily during the experiment. In the fed group, 1 EC ASA tablet (containing $100 \mathrm{mg}$ ASA) was administered p.o. once daily after the morning meal for 7 days, whereas in the fasted group, EC ASA was given in the morning after an overnight fast. The animals were sacrificed $24 \mathrm{~h}$ after the final EC-ASA dose and mucosal lesions in the GI tract were examined. RESULTS: 1) EC ASA tablet did not cause any visible lesions in the stomach. In the fasted condition, EC ASA given orally once a day for 7 days caused mild lesions in the duodenum and small intestine; the mean lesion area (MLA) was $0.17 \pm 0.07 \mathrm{~cm} 2$ and $0.23 \pm 0.07 \mathrm{~cm} 2$, respectively. When EC ASA was given after feeding of regular dry food (Dry) containing $2.8 \% \mathrm{DF}$, the duodenal and intestinal lesions were markedly increased; the MLA was $0.95 \pm 0.11 \mathrm{~cm} 2$ and $1.11+0.31 \mathrm{~cm} 2$ ( $\mathrm{P}<0.01$ and $0.05 \mathrm{vs}$, fasted), respectively. 2) In the cats ate canned food (Can) containing $0.4 \% \mathrm{DF}$, the lesions were markedly decreased; the MLA was $0.01 \pm 0.01 \mathrm{~cm} 2$ and $0.08 \pm 0.05 \mathrm{~cm} 2(\mathrm{P}<0.001$ and 0.01 vs. Dry), respectively. The addition of insoluble DF (cellulose $6 \%$ ) to the canned food appeared the lesions again; the MLA was $0.32 \pm 0.20 \mathrm{~cm} 2$ and $0.69 \pm 0.32 \mathrm{~cm} 2$ ( $P<0.05$ vs. Can), respectively. The addition of soluble DF (pectin 6\%) to dry food markedly decreased the lesions; the MLA was $0.07 \pm 0.07 \mathrm{~cm} 2$ and $0.10 \pm 0.03 \mathrm{~cm} 2$ ( $P<0.001$ and 0.01 vs. Dry). 3) Neomycin (20 mg/kg, p.o.) given $30 \mathrm{~min}$ before morning meal (Dry) for 7 days decreased the lesions in the small intestine, the MLA was $0.21 \pm 0.03 \mathrm{~cm} 2$ ( $\mathrm{P}<0.05$ vs. Dry). CONCLUSIONS: 1) Adverse effects of EC ASA on the duodenal and intestinal mucosa depend on the feeding conditions (fasted or fed) when EC ASA was administered, i.e., the lesions were markedly increased when EC ASA was given after feeding of dry food. 2) Contents of diet, especially insoluble DF such as cellulose and soluble DF such as pectin, play an important role in the formation and prevention of duodenal and intestinal lesions induced by EC ASA. 3) Gram negative enterobacteria such as E. coli may play some role in the formation and aggravation of intestinal lesions. 